\title{
FATORES PROGNÓSTICOS DE LETALIDADE NA MENINGOENCEFALITE TUBERCULOSA
}

\author{
CEUCI NUNES ${ }^{*}$ SERRIO CUNHA **, IRENIO GOMES ${ }^{* * *}$, RITA LUCENA ${ }^{* * *}$, \\ DILCINEIA MORAES ${ }^{* * *}$, AILTON MELO***
}

\begin{abstract}
RESUMO - Este é um estudo de prognóstico em que é avaliada uma coorte retrospectiva de 231 pacientes com diagnóstico de meningoencefalite tuberculosa, com o objetivo de determinar os fatores prognósticos de letalidade. A idade variou de menos de 1 a 68 anos, com 97 pacientes (42\%) na faixa etária igual ou inferior a 4 anos. Em 62 casos ocorreu a confirmação diagnóstica por líquor (cultura, baciloscopia, PCR) ou necropsia; nos demais casos o diagnóstico foi baseado em critérios clínicos, epidemiológicos e resposta terapêutica. Na análise multivariada observamos que os fatores prognósticos mais importantes foram: faixa etária menor que 4 anos, ocorrência de convulsão e alterações de consciência consideradas graves.
\end{abstract}

PALAVRAS-CHAVE: meningoencefalite tuberculosa, meningite tuberculosa, tuberculose do sistema nervoso central, prognóstico.

\section{Prognostic factors for tuberculous meningoencephalitis lethality}

ABSTRACT - In order to describe the lethality predictors of patients with tuberculous meningoencephalitis, records of 231 patients were analysed. Ages ranged from less than 1 year to 68 years. Ninety-seven patients (42\%) were four years old or less. Apart from $73.2 \%$ of patients whose diagnosis was performed by clinical and epidemiologic criteria associated with response to specific therapy, $26.8 \%$ had diagnostic confirmation through cerebrospinal fluid (culture, bacilloscopy, PCR) or necropsy. The lethality predictors were: less than 4 years of age, seizures, and severe alterations of consciousness.

KEY WORDS: tuberculous meningitis, central nervous system tuberculosis, neuro-tuberculosis, prognostic.

A tuberculose é a principal causa de morte por agente infeccioso único e, devido ao aumento do número de casos e das formas multirresistentes, foi colocada em 1993 pela OMS como em estado de emergência no mundo ${ }^{1}$. A meningoencefalite tuberculosa é a mais grave forma dentre as extrapulmonares, tem alta taxa de letalidade e alta frequência de sequelas neurológicas graves e incapacitantes ${ }^{2,3}$.

Poucos estudos específicos sobre fatores prognósticos para letalidade foram encontrados na literatura revisada. Nestas publicações a idade (principalmente os extremos), a duração da enfermidade, o estágio clínico, a presença de déficits neurológicos, a negatividade da reação de Mantoux, a associação com outras formas de tuberculose, a associação com outras doenças, as características liquóricas e a resistência primária aos tuberculostáticos são destacados ${ }^{4-7}$.

No presente artigo, avaliamos os fatores prognósticos para letalidade intra-hospitalar em 231 pacientes com diagnóstico de meningoencefalite tuberculosa internados no Hospital Couto Maia em Salvador, Bahia.

*Hospital Couto Maia; **Departamento de Medicina Preventiva da Faculdade de Medicina da Universidade Federal da Bahia (FAMED/UFBA); ***Divisão de Neuroinfectologia e Neuroepidemiologia do Departamento de Neuro-Psiquiatria da FAMED/UFBA. Aceite: 20-agosto-1998.

Dr. Ailton Melo - Av. Magalhães Neto, 735/802 - 41820-020 Salvador BA - Brasil. E-mail: nnb@cpunet.com.br 


\section{MÉTODOS}

Trata-se de estudo de prognóstico, no qual estudamos uma coorte retrospectiva composta por 231 pacientes com diagnóstico presuntivo ou confirmado laboratorialmente de meningoencefalite tuberculosa, com o objetivo de avaliar os fatores prognósticos de letalidade intra-hospitalar. Todos os casos estudados foram internados no Hospital Couto Maia e faziam parte de três bancos de dados que foram utilizados em pesquisas de meningites. $\mathrm{O}$ primeiro, composto por 99 pacientes com meningoencefalite tuberculosa, utilizado numa pesquisa nacional do Ministério da Saúde em 1983, o segundo com dados de prontuário de 1700 pacientes com meningite, colhidos entre 1990 e 1992, e o terceiro com dados de 809 pacientes colhidos prospectivamente, entre março e dezembro de 1994.

Nos 2608 casos que compunham os bancos de dados citados, foram aplicados critérios de exclusão: 1. pacientes transferidos; 2 . que receberam alta sem terem feito uso de antibióticos ou esquema tríplice; 3 . aqueles que apresentavam as seguintes características: cultura positiva no líquor (LCR) ou no sangue para bactérias ou fungos; presença de bactérias pelo método de Gram; tinta da China para criptococo positiva no LCR; celularidade no LCR maior que 2000 células $/ \mathrm{mm}^{3}$; celularidade maior que 1000 células $/ \mathrm{mm}^{3} \mathrm{com}$ predominância de neutrófilos, uso de tuberculostáticos antes da admissão hospitalar. Após esta seleção foram considerados todos os casos confirmados de meningite tuberculosa, identificados a partir do LCR (coloração pelo método de Ziehl, cultura, PCR) ou necropsia, independentemente do uso ou não do esquema tríplice, e os casos com diagnóstico provável, que apresentavam as seguintes características: 1 . celularidade no $L C R \geq 10 \leq 1000$ células $/ \mathrm{mm}^{3}$, com predominância de linfócitos; 2. proteinorraquia $\geq 60 \mathrm{mg} / \mathrm{dL} ; 3$. resposta terapêutica satisfatória ao esquema tríplice tuberculostático.

Nos pacientes que preenchiam os critérios de inclusão foram analisados os parâmetros demográficos (sexo, idade, procedência e ano do diagnóstico), clínicos e laboratoriais, e comparadas as características entre casos confirmados com os prováveis e entre todos os casos e o desfecho. Dentre as variáveis clínicas, dividimos as alterações do nível de consciência em leve (presença de irritabilidade, sonolência ou Glasgow $\geq 10$ ) e moderado/ grave (presença de coma ou com Glasgow < 10).

Na primeira etapa do estudo estatístico foi feita análise univariada, em que foram utilizados o teste do $\chi 2$ ou o teste exato de Fisher para avaliação das variáveis categóricas, e o teste não paramétrico de Mann-Whitney para variáveis contínuas ou discretas. Na etapa seguinte, foi realizada análise multivariada utilizando-se a técnica de regressão logística. Para a análise estatística foram utilizados os programas EPI INFO versão 6.0 e o SPSS/PC versão 3.1 .

\section{RESULTADOS}

Foram estudados 231 pacientes que preencheram os critérios definidos, sendo 127 (55\%) do sexo masculino e 104 (45\%) do sexo feminino. As idades variaram de menos de 1 ano a 68 anos e $42 \%$ dos pacientes tinham idade igual ou inferior a 4 anos.

Tabela 1. Evolução dos 231 casos de meningoencefalite tuberculosa de acordo com a faixa etária.

\begin{tabular}{cccc}
\hline Faixa etária & $\mathrm{N}(\%)$ & Óbito & Alta \\
\hline $0-4$ anos & $97(42,0)$ & $74(76,3)$ & $23(23,7)$ \\
$5-14$ anos & $46(19,5)$ & $17(36,9)$ & $29(63,0)$ \\
$15-24$ anos & $30(13,0)$ & $17(56,6)$ & $13(43,3)$ \\
$25-34$ anos & $29(12,6)$ & $11(37,9)$ & $18(62,1)$ \\
$35-44$ anos & $18(7,8)$ & $12(66,6)$ & $06(33,3)$ \\
$45-55$ anos & $06(2,6)$ & $02(33,3)$ & $04(66,6)$ \\
$>55$ anos & $05(2,2)$ & $02(40,0)$ & $03(60,0)$ \\
Total & $231(100)$ & $135(58,4)$ & $96(41,6)$ \\
\hline
\end{tabular}

$\chi^{2}=9,007 \quad \mathrm{p}=0,008$ 
Os principais sinais e sintomas registrados nos 231 casos estudados foram: rigidez de nuca (85\%); febre (81,2\%); alteração do nível de consciência $(79,2 \%)$, variando de sonolência a coma; convulsão (48,1\%); e cefaléia (47,5\%). O tempo de doença variou de algumas horas (paciente chegou ao hospital no mesmo dia do início dos sintomas) a 90 dias: média $=10,71$; desvio padrão $(\mathrm{dp})=$ 11,57 .

O estudo do LCR mostrou celularidade média de 288,32 células $/ \mathrm{mm}^{3}$ ( $\left.\mathrm{dp}=270,85\right)$; proteinorraquia média de $182,47 \mathrm{mg} / \mathrm{dL}(\mathrm{dp}=101,08)$ e glicorraquia média de $42 \mathrm{mg} / \mathrm{dL}(\mathrm{dp}=13,2)$.

Dos 231 pacientes, $146(63,2 \%)$ usaram o esquema terapêutico específico para tuberculose e $68(29,4 \%)$ não utilizaram; em 17 (7,4\%) não foi possível a obtenção deste dado. Quanto ao uso de corticóide, ele foi prescrito para $114(49,4 \%)$ pacientes, não utilizado em $78(33,8 \%)$ e em 39 (16,8\%) prontuários não foi possível a obtenção do dado.

Tabela 2. Análise Univariada - Evolução dos casos de meningoencefalite tuberculosa de acordo com as características clínicas e demográficas.

\begin{tabular}{|c|c|c|c|}
\hline Característica & Alta & Óbito & $\mathrm{P}$ \\
\hline \multicolumn{4}{|l|}{$\operatorname{Sexo}(\mathrm{n} / \%)$} \\
\hline $\mathrm{F}$ & $46(46,4)$ & $58(43,0)$ & \\
\hline M & $50(53,3)$ & $77(57,0)$ & \\
\hline Idade em meses (média \pm desvio padrão) & $6,71 \pm 2,29$ & $5,75 \pm 3,48$ & \\
\hline Idade em anos (média \pm desvio padrão) & $17,57 \pm 15,43$ & $11,96 \pm 14,83$ & $*$ \\
\hline $\begin{array}{l}\text { Procedência }(\mathrm{n} / \%) \text { : } \\
\text { interior } \\
\text { capital }\end{array}$ & $\begin{array}{l}16(17,0) \\
74(78,7)\end{array}$ & $\begin{array}{l}34(26,6) \\
93(72,7)\end{array}$ & \\
\hline Tempo de doença (média \pm desvio padrão) & $11,0 \pm 12,7$ & $10,5 \pm 10,3$ & $*$ \\
\hline Febre $(\mathrm{n} / \%)$ & $68(71,6)$ & $105(77,8)$ & \\
\hline Cefaléia (n / \%) & $27(15,1)$ & $28(37,2)$ & \\
\hline Rigidez de nuca (n / \%) & $75(79,8)$ & $101(78,9)$ & \\
\hline Convulsão (n / \%) & $16(16,8)$ & $61(45,9)$ & $*$ \\
\hline $\begin{array}{l}\text { Alteração da consciência } \\
\text { leve } \\
\text { moderada/grave }\end{array}$ & $\begin{array}{l}25(27,8) \\
29(32,2)\end{array}$ & $\begin{array}{l}42(33,6) \\
68(54,4)\end{array}$ & $\begin{array}{l}* \\
* *\end{array}$ \\
\hline Celularidade no LCR (média \pm desvio padrão) & $310,9 \pm 279,0$ & $276,1 \pm 203,5$ & \\
\hline Glicose no LCR (média \pm desvio padrão) & $44,1 \pm 11,8$ & $41,3 \pm 13,7$ & \\
\hline Proteína no LCR (média \pm desvio padrão) & $173,5 \pm 94,8$ & $188,89 \pm 105,24$ & \\
\hline Uso esquema tríplice & $74(87,1)$ & $72(55,8)$ & $* *$ \\
\hline Uso corticóide & $52(67,5)$ & $62(53,9)$ & \\
\hline \multicolumn{4}{|l|}{ Grupo } \\
\hline Confirmados & $16(16,7)$ & $46(34,1)$ & \\
\hline Prováveis & $80(83,3)$ & $89(65,9)$ & \\
\hline
\end{tabular}

$* 0.01 ; * * 0.001$ 
Tabela 3. Análise multivariada. Evolução dos casos de meningoencefalite tuberculosa de acordo com as características clínicas e demográficas (etapas inicial e final da regressão logística múltipla).

\begin{tabular}{lccccccccc}
\hline & \multicolumn{1}{c}{ Etapa inicial } & \multicolumn{5}{c}{ Etapa final } \\
\hline Variável & $\mathrm{N}$ & $\Psi$ & $95 \%$ & $\mathrm{CI} \Psi$ & $\mathrm{P}$ & $\mathrm{N}$ & $\Psi$ & $95 \%$ CI $\Psi$ & $\mathrm{P}$ \\
\hline Sexo & 231 & 1,224 & $0,72-2,07$ & 0,456 & & & \\
Celularidade no LCR* & 230 & 1,752 & $1,01-3,03$ & 0,0446 & & & \\
Convulsão & 160 & 3,722 & $1,85-7,49$ & 0,0001 & 160 & 0,421 & $1,50-7,83$ \\
Uso Corticóide & 192 & 1,778 & $0,97-3,24$ & 0,059 & & & & \\
Alteração de consciência grave & 207 & 2,523 & $1,42-4,47$ & 0,001 & 207 & 0,398 & $1,18-5,62$ & 0017 \\
Alteração de consciência leve & 207 & 1,297 & $0,71-2,36$ & 0,391 & & & & \\
Proteína no LCR & & & & & \\
Glicose no LCR & 230 & 1,001 & $0,97-1,03$ & 0,251 & & & & \\
Faixa etária de zero a 4 anos & 230 & 0,983 & $0,96-1,00$ & 0,104 & & & & \\
Tempo de doença & 231 & 3,850 & $2,16-6,87$ & 0,000 & 231 & 3,850 & $1,08-5,52$ & 0,032 \\
Celularidade no LCR & 223 & 0,996 & $0,97-1,02$ & 0,734 & & & & \\
Glicose no LCR** & 230 & 1,590 & $0,78-3,22$ & 0,198 & & & & \\
Tempo de doença*** & 230 & 1,8293 & $1,02-3,29$ & 0,040 & & & & \\
Proteína no LCR ${ }^{\$} * * *$ & 223 & 1,102 & $0,64-1,88$ & 0,720 & & & & \\
\hline
\end{tabular}

\$Variáveis quantitativas; *Celularidade no LCR com ponto de corte em 300 células $/ \mathrm{mm}^{3} ; * *$ Glicose no LCR com ponto de corte em $49 \mathrm{mg} / \mathrm{dl}$; ***Tempo de doença com ponto de corte em 7 dias.****Proteína no LCR com ponto de corte em $300 \mathrm{mg} / \mathrm{dL}$; $\Psi$ : odds ratio.

Dentre os 231 casos analisados, em 62 (26,8\%) houve confirmação diagnóstica de meningoencefalite tuberculosa. Em 25 pacientes a necropsia firmou o diagnóstico, a pesquisa direta de BAAR no líquor foi positiva em três, a cultura em 36, PCR em 12. Em 14 casos a confirmação diagnóstica ocorreu por mais de uma forma. Em 169 pacientes (73,2\%) o diagnóstico foi considerado provável por ter sido feito com base em informações clínicas, quadro do líquor e resposta ao tratamento específico.

$\mathrm{Na}$ análise univariada quando comparamos os casos que evoluíram para óbito com os que tiveram alta hospitalar observamos diferença na idade, quando estratificamos por faixa etária (Tabela 1). Quanto ao sexo, à procedência (se da capital ou do interior do Estado) e ao tempo de doença, os grupos foram semelhantes. As características clínicas como febre, cefaléia, rigidez de nuca foram igualmente distribuídas entre os casos que evoluíram para alta ou óbito. Já as alterações neurológicas, como convulsão, alteração do nível de consciência e alteração de nervos cranianos, ocorreram com mais frequência nos pacientes que evoluíram para óbito que nos que receberam alta (Tabela 2). As alterações liquóricas de celularidade, glicose e proteína mostraram-se semelhantes em ambos os grupos; entretanto no caso da glicose e da celularidade quando estratificados, a primeira com ponto de corte em 45 e a segunda em 300, foi observada diferença significante. Não encontramos evento semelhante na análise de proteína.

Na regressão logística, utilizando o método de "stepwise", as variáveis preditoras de letalidade foram: alteração de consciência grave (coma), convulsão e faixa etária de 0 a 4 anos (Tabela 3). 


\section{DISCUSSÃO}

Este estudo mostra ligeira predominância dos casos de meningoencefalite tuberculosa no sexo masculino (1,2:1), grande concentração de casos na faixa etária de 0 a 4 anos (42\%) e pequeno número de casos em maiores de 55 anos $(2,2 \%)$. A alta prevalência dessa infecção na faixa etária de 0 a 4 anos é determinada pelo estreito contato intra-domiciliar com pacientes bacilíferos ${ }^{8}$.

A gravidade da meningoencefalite tuberculosa é reafirmada pela alta taxa de letalidade $(58,6 \%)$, que se acentua ainda mais nos menores de 4 anos (76,3\%). Esta taxa calculada para os 231 casos agora estudados, reproduz os achados referentes aos 99 casos estudados na Bahia em 1983, que foi $55,3 \%{ }^{9}$. Em outros países em desenvolvimento taxas também elevadas de letalidade foram observadas, como as descritas no Chile por Valenzuela e col. $(32,6 \%)$ e na India por Singh e col. $(43,4 \%)^{6,7,10}$.

Em relação ao diagnóstico etiológico, este estudo reafirma as dificuldades de vários Serviços, quanto ao estabelecimento de um padrão-ouro para diagnóstico. A cultura do LCR continua a representar a mais específica forma de confirmação no entanto com tempo de determinação muito longo e sensibilidade baixa. Técnicas mais modernas, como PCR e outros testes de amplificação do DNA, são promissoras; entretanto não estão disponíveis na nossa prática clínica diária ${ }^{11}$.

$\mathrm{Na}$ avaliação dos fatores prognósticos, na análise univariada, algumas variáveis estavam relacionadas com o óbito, como: faixa etária de 0-4 anos; convulsão; alteração do nível de consciência; confirmação diagnóstica; ano de internamento; glicose menor que $45 \mathrm{mg} / \mathrm{dL}$; celularidade no líquor inferior a 300 células $/ \mathrm{mm}^{3}$. Algumas destas variáveis mantiveram a sua importância na fase inicial da regressão logística múltipla, quando foram avaliadas todas as variáveis conjuntamente, como a faixa etária, a convulsão, o coma, a glicorraquia e a celularidade no líquor. Entretanto com a continuação da análise, quando as variáveis de menor importância foram retiradas, foi observado que convulsão, alteração de consciência grave e faixa etária de $0-4$ anos são os principais determinantes de óbito nesta população.

A literatura estudada mostra unanimemente a idade como fator prognóstico importante, principalmente os extremos, menores de 4 anos e maiores de $55 \operatorname{anos}^{4,6,7}$. No presente estudo, como apenas 5 casos compunham a faixa etária de maiores de 55 anos, a avaliação foi prejudicada. A gravidade dos casos de tuberculose em crianças acontece mesmo quando não existe comprometimento neurológico.

O comprometimento acentuado do nível de consciência caracteriza o estágio III da doença que está relacionado ao óbito numa frequência de $46-100 \%{ }^{6,7,12}$. Este estudo mostra que alguns pacientes, mesmo com curto tempo de doença, já chegam ao hospital em estágios avançados, limitando a atuação médica. A agressividade da doença observada nestes casos pode ser multifatorial, relacionada à virulência do bacilo, carga bacilar ou a características do hospedeiro a exemplo da desnutrição, alcoolismo e associação com outras doenças ${ }^{1,8}$.

Em outros estudos, convulsão foi também determinada como fator prognóstico, e Misra e col. estabeleceram que sua ocorrência estava relacionada à presença de infarto cerebral, o que não foi avaliado nesta pesquisa ${ }^{13,14}$.

As alterações liquóricas foram relacionadas ao prognóstico por Singh e col., sendo descrita maior letalidade nos pacientes com glicose abaixo de $40 \mathrm{mg} / \mathrm{dL}$, proteínas acima de $200 \mathrm{mg} / \mathrm{dL}$ e cloretos abaixo de $650 \mathrm{mg} / \mathrm{dL}^{6}$. No nosso estudo não conseguimos observar a associação de características liquóricas com letalidade.

O tempo de doença, ao contrário do que foi encontrado por outros autores ${ }^{4,5}$, não foi diferente entre os casos que evoluíram para óbito e os que receberam alta. Como em nossa casuística grande número de casos teve tempo de doença curto, isto pode indicar uma agressividade maior da infecção, justificando a alta taxa de letalidade observada em nossa população. A mensuração do tempo real de 
doença numa população com grande número de crianças pode também ser prejudicada, devido ao nível baixo de informação observada nesta faixa etária.

O uso de corticosteróides, embora recomendado oficialmente no Brasil, não está definido como fator prognóstico para letalidade ${ }^{1,15}$. Neste estudo observamos que o uso de corticoesteróides ocorreu em 59,4\% dos pacientes. Este fato pode ter ocorrido devido a insegurança do médico quanto ao diagnóstico, o que faz com que use apenas o esquema tríplice.

Algumas variáveis descritas como indicadoras de prognóstico, como a reação de Mantoux e a associação com outras formas de tuberculose ${ }^{7}$, não foram avaliadas por falta destes dados nos prontuários.

Algumas limitações deste estudo foram observadas. O fato de ser um estudo retrospectivo, cuja coleta de dados não foi planejada, prejudica a avaliação de algumas variáveis importantes como dados epidemiológicos para tuberculose, uso ou não de BCG e associação com outras doenças como por exemplo a AIDS. Da mesma forma, o fato de terem sido os dados coletados em prontuários no segundo banco de dados e prospectivamente nos dois outros, pode ter levado a viés de informação.

Diante dos dados avaliados, a prevenção desta doença precisa ser enfatizada. Uma proteção maior às crianças, principalmente entre 0 e 4 anos, em que a taxa de letalidade e morbidade são elevadas, faz-se necessária ${ }^{3}$. O aumento da cobertura vacinal com BCG, considerada pela OMS como prevenção efetiva das formas graves da doença, a busca ativa de casos e a introdução precoce do tratamento adequado são medidas que podem ajudar na reversão deste quadro epidemiológico ${ }^{1,16}$.

Podemos concluir que a meningoencefalite tuberculosa continua sendo uma doença grave em nosso meio, que os principais preditores de letalidade são: faixa etária de 0 a 4 anos, convulsão e coma. Neste estudo as características liquóricas não foram relacionadas ao prognóstico, assim como o tempo de doença.

Agradecimentos - 1. Aos médicos do Hospital Couto Maia, Adelcy Tavares e Nilton Gomes, por permitirem a utilização dos dados colhidos em 1983; 2. aos profissionais do Hospital Couto Maia cuja organização do SAME permitiu a obtenção de dados fundamentais; 3. ao professor Aníbal Silvany Neto (Departamento de Medicina Preventiva-UFBA) pela ajuda fundamental na análise estatística.

\section{REFERÊNCIAS}

1. Brasil. Ministério da Saúde. Manual de Normas para o Controle da Tuberculose / Ministério da Saúde, Fundação Nacional de Saúde, Centro Nacional de Epidemiologia, 1995.

2. Nunes C, Gomes I, Tavares A, Melo A. Características clínicas e laboratoriais de 62 casos de meningoencefalite tuberculosa. Arq Neuropsiquiatr 1996;54:222-226.

3. Zuger A, Lowy F. Tuberculosis of the central nervous system. In Sheld WM, Whithey RJ, Durack DT (Eds). Infections of the central nervous system. New York: Raven Press, 1991:425-739.

4. Azambuja HCP, Picon PD, Rizzon CFC, Coutinho M. Meningite tuberculosa. In: Picon PD, Rizzon CFC, Ott WP (Eds) Tuberculose: epidemiologia diagnóstico e tratamento em clínica e saúde pública, Rio de Janeiro: MEDSI, 1993:433-452.

5. Kennedy DH, Fallon RJ. Tuberculous meningitis. J Am Med Assoc 1979;241:264-268.

6. Singh NK, Singh P, Tripathi K, Sruvastava PK, Singh DS. Prognostic factors and sequelae of tuberculous meningitis in adults. J Ind Med Assoc 1985;83:50-53.

7. Valenzuela MT, Carrasco E, Garcia P, Toro J. Analisis retrospectivo del prognóstico de la meningitis tuberculosa en Chile, en relacion al diagnostico y al tratamiento. Enf Resp Cir Tor 1988;4:124-132.

8. Brasil. Ministério da Saúde. Controle da Tuberculose: uma proposta de integração ensino-serviço, 3a. edição rev. Rio de Janeiro: CNTC/NUTES, 1992.

9. Martins TS, Medeiros CO, Gerhardt GF. Meningite tuberculosa (resultados de uma pesquisa operacional). J Bras Med 1985;4:34 -41.

10. Davis LE, Rastogi KR, Lambert LC, Skipper BJ. Tuberculous meningitis in the Southwest United States: a communitybased study. Neurology 1993;43:1775-1778.

11. Catanzaro A. Value of direct amplified test for diagnosis of tuberculosis. Lancet 1996;347:1500-1501.

12. Carrasco EC. Nuevas expectativas en el tratamiento y prognostico de la meningitis tuberculosa. Enferm Cir Tor $1988 ; 4: 122-123$.

13. Gomes I, Melo A, Lucena R, et al. Prognosis of bacterial meningitis in children. Arq Neuropsiquiatr 1996;54:407-411.

14. Misra UK, Kalita J,Srivastava M, Mandal SK. Prognosis of tuberculous meningitis: a multivariate analyses. J Neurol Sci 1996;137:57-61.

15. Holdiness MR. Menagement of tuberculosis meningitis. Drugs 1990;39:224-232.

16. Wunsch V Filho, Castilho EA, Rodrigues LC, Huttly SRA. Effectiveness of BCG vaccination against tuberculous meningitis: a case control study in São Paulo, Brazil. Bull of the WHO 1990;68:69-74. 